\title{
SIII
}

\section{Studies in Second Language Learning and Teaching}

Department of English Studies, Faculty of Pedagogy and Fine Arts, Adam M ickiewicz University, Kalisz

\section{Beliefs and experiences in the English classroom: Perspectives of Swedish primary school learners}

\author{
Maria Nilsson \\ Stockholm University, Sweden \\ https://orcid.org/0000-0003-4201-0867 \\ maria.nilsson@isd.su.se
}

\begin{abstract}
This study investigates how Swedish learners make sense of and perceive English instruction and the process of foreign language learning in a target language-only primary school classroom. In small group discussions, 26 learners aged 9-10 were audio recorded while discussing questions related to their language learner beliefs and their classroom experiences. Learners expressed a strong consensus about the importance of both the teacher's extensive target language input and the learners' oral engagement, in alignment with the beliefs of the teacher. However, the analysis identified three mismatches among high anxiety learners in this context, related to incomprehensible teacher talk, social fear of making mistakes and classroom organization. As their voiced beliefs were at odds with their emotionally guided behavior of refraining from asking questions or volunteering to speak, their sense of agency was reduced. In this context, the target language-only approach appeared to have a negative impact on the emotional, organizational and instructional dimensions of foreign language instruction for many of the young learners. The findings illustrate the interrelated dynamics of beliefs, emotions and classroom context, and contribute to our understanding of learners' foreign language anxiety and sense of agency in the primary foreign language classroom.
\end{abstract}

Keywords: young language learners; learner beliefs; target language use; foreign language anxiety; sense of agency 


\section{Introduction}

The number of young learners of English as a foreign language around the world has increased dramatically during the last decade (Garton \& Copland, 2019). However, little is still known about foreign language education for young language learners (YLLs) as compared to adult foreign language instruction. Approaches from adult education, such as exclusive target language (TL) use and communicative language teaching (CLT), have been adopted without considering whether they are appropriate for the age group and without concern for the realities of classroom instruction in different contexts (Garton \& Copland, 2019). A large mixed methods study involving more than 4,000 teachers in 142 countries found that the most challenging aspects of teaching, according to the participants, were implementing CLT and making young learners speak English (Copland, Garton, \& Burns, 2014). Other issues of concern were how to deal with a lack of motivation, discipline, class size and the diversity of language proficiency.

However, the perspectives of YLLs themselves are seriously under-researched (M uñoz, 2017). A deeper understanding of how YLLs within mandatory education may perceive language learning and the instruction they receive, can inform the development of age appropriate teaching approaches that consider cognitive, emotional as well as social needs of learners. Since negative emotions that develop in early education are known to have long-term effects on motivation and self-esteem (Mihaljević Djigunović, 2009), more research is needed that considers a holistic perspective on learning and takes into account the complex interplay between YLLs' cognition, emotion and the classroom context. Such interaction involves, for example, learner beliefs, which entail different aspects of learners' meaning-making in connection to language learning and instruction (Kalaja, Barcelos, \& Aro, 2018).

The purpose of this study is to explore YLLs' beliefs about foreign language teaching and learning in relation to their own classroom experiences. M ore specifically, the focus is on how learners with varying degrees of foreign language anxiety (FLA) perceive English instruction and their own classroom participation. In a previous study, Swedish YLLs aged 8-12, in ten classrooms, completed a questionnaire targeting FLA, where learners reported their reactions to oral classroom interaction (Nilsson, 2019). The present study is based on qualitative data from group discussions with learners from the classroom where the highest mean level of FLA was reported and where many of them frequently experienced negative emotions in relation to English lessons. 


\section{Background}

\subsection{Learner beliefs}

Language learner beliefs encompass "the conceptions, ideas, and opinions learners have about L2 learning and teaching and language itself" (Kalaja et al., 2018, p. 222). Such beliefs have attracted attention since the late 1980 's, in parallel with the introduction of CLT and an increasing interest in the learner (Kalaja \& Barcelos, 2013). In a pioneering study, Horwitz (1988) set out to raise awareness of common learner beliefs among adult students, many of which were considered unrealistic and counterproductive. In such early studies, beliefs were seen as rather stable preconceptions residing in the mind of individual learners.

Since then, more contextual approaches have been implemented that consider the voices and experiences of learners and their interpretations of learning (Kalaja, Barcelos, Aro, \& Ruohotie-Lyhty, 2016). From this perspective, learner beliefs emerge in the learning context as a result of an ongoing meaningmaking process of interaction. Dufva (2003) highlights that communication and cognition are integrated and that beliefs take shape as they are formulated and negotiated in interaction with others. This may be especially true for children, who have less experience of language instruction and are generally less used to talking about their learning.

Learner beliefs have social origin as they are influenced by significant others and norms in society at large, and develop in response to the environment (Aro, 2009). At the same time, each individual has a unique subjective perspective, anchored in personal experiences. In relation to foreign language learning, such experiences refer to our accumulated perceptions, which involve both cognitive and emotional processes, resulting from the situated learning environment (Csizér \& Kálmán, 2019). There is a reciprocal interaction between beliefs and experiences. On the one hand, our beliefs influence our understanding and recollection of our personal experiences. On the other hand, these experiences help us maintain or renegotiate these same beliefs (Kalaja et al., 2018). Learner beliefs are therefore social, dynamic and contextual. Furthermore, they are personal and unique but also collective. For example, Dufva (2003) found that adults who were asked to share their language learner beliefs often referred back to experiences from childhood. Although such memories were quite personal, incidents that took place within the same educational context often resembled each other, generating rather similar beliefs. Findings like these also point to more stable aspects of learner beliefs, where beliefs that are established early on and connected to emotional incidents often remain influential (Barcelos \& Kalaja, 2013). 
Rather than pinning down certain learner beliefs, recent studies focus more on how beliefs develop and guide learners' behaviors and approaches to language learning in specific contexts. M ismatches between adult students' and teachers' preferred teaching approaches in language education may, for example, cause frustration for both parties (Brown, 2009). In order to gain a deeper understanding of the role of beliefs in instructed language learning, Kalaja et al. (2018) have called for research on a broadened range of learner beliefs and related aspects, such as affect and agency.

\subsection{Beliefs, emotion and sense of agency}

The influence of emotions on our thinking, perception, sense-making, and learning has been acknowledged in research (Arnold, 2011). M ahn and John-Steiner (2002) have even pointed out that the notion of the zone of proximal development (ZPD) cannot be fully understood without recognizing the interaction between cognition and emotion. Negative emotions make learners less focused on a task while also making the learning experience itself less pleasant, and therefore less effective (Arnold, 2011).

The relationship between beliefs and emotion is reciprocal. Horwitz (1988) highlighted the detrimental impact that certain beliefs may have on language learning and thus contribute to FLA, for instance, beliefs related to the importance of accuracy. In turn, emotionally loaded experiences of joy, anxiety or embarrassment may have a pervasive impact on our language learner beliefs (Dufva, 2003) and beliefs about ourselves as language learners, that is, our selfconcept (M ercer, 20011). This self-concept involves both cognitive and affective dimensions and is linked to confidence and evaluations of our ability to learn and perform. Self-concept and beliefs about language learning, in interaction with the social context and the affective atmosphere, contribute to a sense of agency (Mercer, 2011), which refers to our perceived potential to act in a particular environment.

In sum, the way learners make sense of language instruction and language learning involves both rational and affective dimensions. Beliefs and previous experiences are crucial for learners' approaches, perceptions and responses to language instruction and the learning environment. To visualize the impact of emotion on beliefs, agency and identity (the latter will not, however, be discussed further in this paper), Kalaja et al. (2016) suggest a model, presented in Figure 1, where emotion serves as background to the other three overlapping constructs (see Figure 1). 


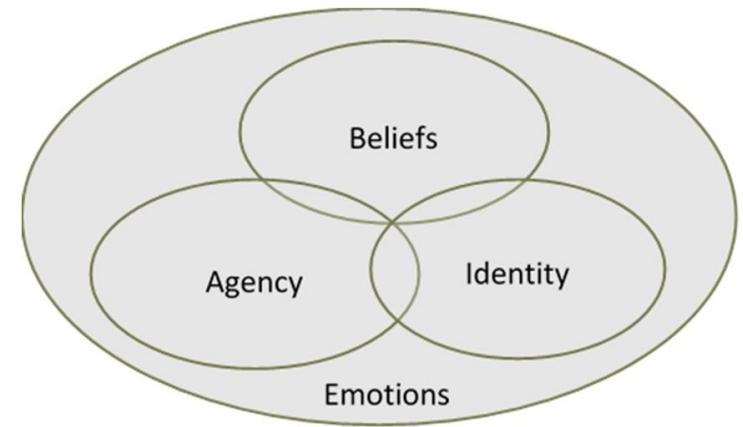

Figure 1 The interaction of beliefs, agency, identity and emotion according to Kalaja et al. (2016)

Yet, recent empirical studies from a variety of settings with adult learners have found beliefs that were at odds with emotion and behavior. For instance, learners' perceived risk of social embarrassment resulted in frustration and avoidance behaviors in spite of their expressed beliefs about the importance of interacting in the target language (Aragão, 2011; García-Ponce, Crawford, Lengeling, \& M ora-Pablo, 2018; Gkonou, 2017; Yoshida, 2013). These researchers concluded that teachers should therefore reflect on, address and conduct classroom discussions about beliefs and expectations, to counteract negative emotion. Arnold (2011), however, adds that while this may be important, the most effective boost to learners' self-concept comes from the actual experience of successful interaction in the TL.

\subsection{Studies of children's learner beliefs and experiences}

Although research on YLL beliefs is limited, a number of studies confirm the emergent, social and contextual aspects of such beliefs. Primary school learners are metacognitively aware and able to reflect on their beliefs. In Spain, M uñoz (2014) found that learners aged 7-12 were able to formulate and motivate beliefs and opinions about English learning. Furthermore, they could differentiate between activities they liked and those that they found most beneficial to learning. While they favored listening, they reported learning more from speaking. Kolb (2007) interviewed German learners aged 8-9 and found that they held conceptions about language, ranging along a continuum of atomistic and more holistic views, rather similar to those held by adults, and which were likely to impact on their approach to learning. A longitudinal interview study with 7-11year-olds in Finland highlighted how beliefs were appropriated from the onset of foreign language instruction (Aro, 2009). Pedagogical practices and increasing personal experiences influenced learner beliefs although "authoritative voices" 
(p. 154) affected learners' interpretations of these experiences. This adult influence diminished with age, in support of the claim by M ihaljević Djigunović (2015) that such influence may have been exaggerated and that YLLs form their own beliefs and opinions rather quickly, based on their own foreign language classroom experiences. Cameroon, Kuchah, and Pinter (2012) used a focus group approach with 10-11-year-old participants, aiming to reduce the power imbalance between the researcher and the participants while prompting them to share their thoughts about good teaching. The findings revealed that learners did not share the views of their teachers, and the authors concluded that "affective factors are at the centre of the pedagogic process" (p. 295) for YLLs. They argued that approached with a safe and less formal method of data collection, YLLs may share opinions and explore perspectives that adults may not have expected.

A previous study by Nilsson (2019) adapted the Foreign Language Classroom Anxiety Scale (FLCAS; Horwitz, Horwitz, \& Cope, 1986) to the age, classroom routines and activities in ten Swedish primary classrooms to investigate emotional responses to common classroom practices, such as listening, speaking and volunteering. The findings revealed that $18 \%$ of the 225 learners, aged $8-12$, belonged to the high anxiety category. These high anxiety learners were unevenly distributed across the classrooms and reported frequently feeling uneasy or nervous during English lessons. Speaking and the fear of making mistakes were the top concerns among these learners, echoing similar findings from quantitative YLL studies in other contexts (e.g., M ihaljević Djigunović, 2009 in Croatia; Yim \& Yu, 2011 in Korea). However, more contextualized and qualitative approaches are necessary to gain deeper insight into the experiences of YLLs and illuminate the complexity of early language instruction (Mihaljević Djigunović, 2012; M uñoz, 2017; Yim \& Yu, 2011). The prior study (Nilsson, 2019) that found FLA in all the ten well-functioning classrooms, raised a question about the possibility that more anxious learners hold beliefs and expectations different to those with less FLA. To add to the growing body of research based on the voices of young learners themselves, the present study focuses on one of these classrooms, with the highest levels of FLA, to illustrate the beliefs and experiences among learners with varying levels of FLA within a Swedish context. In addition, the paper explores a new methodological approach in the study of YLL beliefs, by orchestrating simultaneous group discussions without a participating adult.

\subsection{The Swedish context}

In Sweden, English is a mandatory school subject, taught as the first foreign language from grade 3 at the latest, although instruction is common from grade 1, at age 7 . There are no grades awarded until year 6 when national tests are implemented to 
secure that learners have reached an A2.1 level according to CEFR. The amount of teachers' TLuse during English lessons varies as steering documents do not comment on this aspect, until upper secondary school, when teaching should be conducted in English as far as possible (Swedish National Agency for Education, 2011).

English enjoys high status in Swedish society. Swedes are surrounded by English in their daily life (Swedish National Agency for Education, 2011), and Sweden places high in international surveys (e.g., European Commission, 2012). Out-of-school language instruction is rare for primary learners. However, many of them spend a considerable amount of their free time interacting with English online (Sylvén, 2019). This extensive extramural exposure contributes to heterogeneous language proficiency in the classroom.

\section{The study}

\subsection{Aim and research questions}

The study aims to explore learners' beliefs and experiences with regard to the purpose and the process of foreign language teaching and learning in a Swedish year 3 classroom. Furthermore, as 38\% of learners in the class reported frequently experiencing FLA (Nilsson, 2019), the relationship between negative emotions and learner beliefs may be illuminated by comparing data from learners with varying degrees of learner anxiety. Based on group discussions among the 26 participants, the following research questions are addressed:

1. What beliefs and experiences do these young learners express in relation to foreign language instruction?

2. What similarities and differences can be found when comparing the expressed beliefs and experiences of more and less anxious young learners, respectively?

3. Can any conflicting beliefs and experiences be identified, and if so, what are they?

\subsection{Participants}

The class consisted of 29 learners who had all opted for taking part in this study, and consent was obtained from them and their parents/caregivers. However, only 26 of them were present on the day of data collection. The learners, aged 9-10, were in year 3 in a primary school in a socio-economically stable suburb of Stockholm. All learners had Swedish as their L1, according to the class teacher. Consequently, they constituted a relatively homogeneous group regarding age 
and experiences of language instruction and presumably also relatively so regarding socio-economic background. The generalist teacher was certified to teach English and had taught the class since year 1.

\subsection{Classroom context}

Classroom observations were conducted in order to contextualize the study, assert the relevance of the group discussion prompts and facilitate the analysis, as learners made references to their classroom practices and routines. The researcher sat at the back of the classroom as a reactive observer (responding when addressed but otherwise not engaged in the lesson). These observations included morning circle time and the weekly 50-minute English lesson that followed, on three occasions prior to data collection, about 220 minutes in total. In the morning assembly, all learners and their teacher gathered on a carpet to go through the daily information. According to the teacher, part of this $20 \mathrm{mi}-$ nute circle time was conducted in English every day, and once a week, before the English lesson, it was done exclusively in English. During the observations, the teacher used an English-only approach, offering a lot of oral input and with all instructions and explanations in English. On very few occasions, the teacher would add a Swedish word: "Big letters, like when we do crosswords, korsord." On other occasions she would ask learners to translate a word into Swedish: "What does individual mean?" Apart from that, learners were discouraged from speaking in Swedish: "If you want to talk you have to speak English." A few times learners posed questions in Swedish that the teacher replied to in English, adding: "And I only want to hear English."

Activities were mainly teacher-centered. During circle time the teacher spoke to the group, addressed one learner at a time or sent around a question (about, for example, breakfast or a favorite animal) that the learners were to respond to in the circle. Several learners exhibited avoidance behavior or looked confused at times. The teacher would then prompt them with leading questions, or suggest an answer to open questions. During the lessons the learners mostly volunteered by raising their hands. The teacher made frequent use of gestures and objects and used the whiteboard to write words, scaffold phrases and stress certain sounds. Pronunciation was highlighted in a playful way: "I think we all need to say furniture."

Activities involved written individual work and oral pair work where learners practiced vocabulary and sentences based on specific patterns or pictures. The teacher would remind the learners to speak English: "I hear Swedish in here, and I don't like it." From the observations, it was clear that some learners struggled to understand instructions and complete oral activities in pairs, uttering words in quiet voices, seeking confirmation from their peer. At the end of the 
lesson the teacher would state that Swedish was now allowed again. On one such occasion, the teacher brought up her TL-only approach and that although she could understand the students' frustration, it was "the best way to learn languages. Do you remember how you learnt your first language?" This topic did not seem new to the learners but may also have been prompted by the presence of the researcher.

In spite of the rather rigid language policy, the classroom atmosphere was friendly. The teacher was spontaneous, enthusiastic, and showed a clear interest in her learners as individuals. Children were encouraged to help each other. Attempts and guesses were praised. The atmosphere was relaxed and the teacher would openly admit to being uncertain of spelling on a few occasions. Learners seemed fond of their teacher and would approach her for a hug or a chat entering the classroom.

The current classroom can thus be described as supportive, but with high expectations on the learners to tolerate extensive TL input and to attempt to speak English themselves. As indicated by the prior questionnaire study (Nilsson, 2019), 11 learners in this group reported that common classroom practices evoked negative emotions such as anxiety and nervousness. The observations confirmed that apart from circle time, talk time was unevenly distributed and many learners did not volunteer to speak in front of the group.

\subsection{Data collection}

Simultaneous group discussions were conducted, with the researcher present, but not the teacher. The group discussion arrangement allowed participants to benefit from group interaction in a familiar environment to articulate and explore their beliefs in joint sense-making. The design aimed to empower learners to share thoughts, and test, suggest and negotiate ideas, based on their personal experiences within the shared context. Consequently, the group is not considered to interfere or stand in the way of accessing learner beliefs. Instead, the social interaction constitutes the "cognitive workspace" (Dufva, 2013, p. 53) for the participants. The classroom environment and the group dynamics are part of learners' everyday school experience in which their beliefs evolve. Furthermore, the design prevented the negative impact of the power-imbalance in adult-child interaction on children's emotional state and willingness to communicate (Ravet, 2007).

Based on the learners' individual FLA scores from the previous study on FLA (Nilsson, 2019), which were known only to the researcher, learners were seated in groups of 3-4, sharing similar levels of FLA. This was thought to facilitate fruitful interaction between learners, especially those who find speaking English, or oral classroom interaction in general, uncomfortable. Without revealing the rationale behind the group division, the teacher had been consulted to 
suggest any modifications that would be appropriate for social reasons. One such change was made. The teacher was confident that the rationale behind the group arrangement would not in any way be obvious to the children. In one group, mean levels of FLA were quite low, three groups had moderate levels, while the remaining four groups had mean scores that indicated high anxiety. In reality, learners were spread along a continuum of anxiety levels. This division was therefore purely methodological, for the sake of studying possible similarities and differences among learners.

The group discussion activity aimed to engage and interest learners while also being brief enough to maintain their concentration. In their groups, learners took turns drawing questions out of a box, which added a slightly playful element, to read aloud and discuss in Swedish while being recorded on a dictaphone. Based on the researcher's teaching experience and observations in connection to the present project, questions had been formulated and piloted in two other classrooms. In total, there were 13 questions (see Appendix), although all groups did not have the time to discuss them all. The questions were worded in a way that should not guide the learners in a specific direction, while remaining clear in terms of meaning and scope. Learner beliefs in connection to the language learning process were in focus: the value of certain teaching practices, accuracy and intelligibility, guessing, the TL-only approach, how best to learn, and expectations for future proficiency. There were also questions that addressed attitudes to making mistakes and being challenged with new content. While introducing the activity, the researcher encouraged learners to discuss and share their thoughts, not necessarily agree, but elaborate and share the speaking time. The idea that the questions had no right or wrong answers was underscored. The group discussions lasted for 20-28 minutes.

\subsection{Data analysis}

In order to analyze the subjective thoughts and experiences of the participants, qualitative content analysis was conducted, following the guidelines and the terminology of Graneheim and Lundman (2004). Qualitative content analysis focuses on lived experiences and allows researchers to focus on descriptive content, a manifest level, but also on a more interpretative and latent level, to find recurring and underlying themes.

Based on the assumption of the contextual and social dimensions of learner beliefs, utterances were not regarded as personal but rather as generated within the group of a certain anxiety-level and interpreted within the specific conversation, that is, unit of analysis. In other words, although the voice of each individual is considered in the interpretation, each discussion represents 
an event of joint meaning-making, with the analytical focus on beliefs and experiences that emerge within each interaction.

The discussions, a total of 3.5 hours, were transcribed by the researcher, which offered good familiarity with the data. Meaning units addressing beliefs and experiences were identified, most often a phrase or a sentence, sometimes a longer interaction. The observations and recordings served as contextual backdrop facilitating the interpretation as the meaning units were condensed and coded. In this process, care was taken to stay close to the obvious, manifest content, both for the sake of maintaining the children's own words and to avoid the risk of an adult perspective in the interpretation. Initially, codes were printed, cut apart and sorted into tentative categories. All codes were then imported into nVivo 11 and categories were revised further until two major categories were generated, one labeled beliefs and the other experiences. Beliefs include learners' beliefs, assumptions and value judgements on the purpose of studying English and the process of language learning and teaching. Experiences focus on students' perceptions about themselves as language learners and of English as a school subject, memories, descriptions of classroom practices and behavior. The former thus revolve around ideal principles and techniques that should guide teaching and learning whereas the latter represent what learners refer to as actual perceptions, reactions and experiences, which were both cognitive and emotional. Following the abstraction process, the attention was focused on similarities and differences within subcategories in the class as a whole, and between less and more anxious groups within and across each subcategory.

\section{Findings}

The two initial research questions concern the expressed language learner beliefs and experience, and any similarities and differences among more and less anxious learners in this regard. Sections 4.1-4.3 below address this manifest content in the data and focus on learners' beliefs and experiences in relation to oral TL input and output as well as classroom organization during English lessons. In the process of analysis, salient tensions were detected, in response to the third research question which concerned whether conflicting beliefs and experiences could be found. These mismatches are summarized in section 4.4, to synthesize the perspectives of the more anxious young learners. Quotes from the group discussions are included, translated into English. Real names have been replaced with pseudonyms. A group number corresponding to the level of FLA (low anxiety - group LA1, moderate anxiety - groups M A2-MA4 and high anxiety - groups HA5-HA8) follows each excerpt. 


\subsection{Beliefs and experiences related to listening and understanding English}

The learners expressed consensual beliefs about the importance of the teacher's predominant use of English, as it challenged learners to process input, make use of strategies and build vocabulary:

\section{Excerpt 1}

I guess it's good that they can ... that she speaks a lot of English, cause then you have to think a bit, too, like, hm ... what does that sound like? Or what could that be? And things like that ... so I think, it's good. (Aron, LA1)

The value of extensive TL input was recognized in all eight groups, resonating with the approach adopted by the teacher. Although arguing that monolingual teaching was beneficial for language learning, some low and medium anxiety learners also expressed a desire to know exactly what was said and to get the "correct information" (MA3). While the teacher's abundant use of English would help them learn, the absence of translations could cause frustration. Some utterances reflect the idea that it is the responsibility of the teacher to make herself understood and adjust her speech to a level appropriate for the learners. Some suggested the use of more Swedish to summarize information that would follow in English:

\section{Excerpt 2}

Tyra: I think it's easier when someone explains in advance ... you know ... what she is going to say.

Lova: $\quad$ Yes, and what to do.

Tyra: Yes, what to do, cause I usually don't understand what they say in English. (MA4)

The learners thus expressed a concern about not being able to follow the lesson content, calling for some support in the L1. High anxiety learners also spoke of the challenges of not understanding and observations confirmed that several learners were unable to respond to or follow the teacher's instructions. Nevertheless, in spite of these difficulties they maintained that they were positive towards the monolingual approach and questioned it less than their peers. The nervousness or frustration that many articulated was associated with their own output rather than input:

\section{Excerpt 3}

It's hard when our teacher speaks English, sometimes, because sometimes you don't understand and you get like nervous, cause you don't know what to say ... you don't really know what to say ... but ... otherwise I guess it's good. (Bea, HA5) 
In other words, incomprehensible teacher talk was reported to ignite anxiety only when learners were expected to respond in some way. High anxiety learners accepted not understanding as they believed they would learn in the long run, subscribing to an immersive approach to learning where they will acquire the target language with time, as long as it is offered in great quantity":

\section{Excerpt 4}

You learn automatically, you don't even think, you think that it's hard, but then if you don't think you learn automatically, and ... it's because the teacher speaks very much, and then you get more and more into the brain. (Kim, HA6)

Similar thoughts were voiced in all four groups of high anxiety learners, using expressions such as "stick to your brain" (HA7) or "getting into the head" (HA8). Some learners would deal with incomprehensible input by hoping that explanations would follow, while others reported getting by without understanding the teacher's instructions and instead figuring out the activity once they had started working on it.

\subsection{Beliefs and experiences related to speaking English}

All groups discussed the value of listening and/ or speaking in order to learn English. Many low or medium anxiety learners said that they put more weight on listening than speaking, as this offered new input for them to pick up. The high anxiety learners put greater emphasis on speaking and interacting. According to them, they learn best from speaking about everyday topics, using vocabulary that they understand and having to formulate phrases and search for words. All learners highlighted the importance of participating, guessing and trying:

\footnotetext{
Excerpt 5

Erik: The most important thing in English is that you have to dare to speak English.

Bea: $\quad$ Yes ... you have to dare, like, to speak up.

Erik: Speak English.

Sara: $\quad$ Yes, if not, you don't learn anything. (HA5)
}

The sample illustrates beliefs about the role of the learner, recognizing the value of pushing oneself to participate orally. Similar interactions were found in all groups, promoting positive thinking, exerting and believing in oneself, and persevering.

For many less anxious learners, the need to speak English was not a problem: "It feels good to speak English because then you learn a lot, and ... it feels, my whole body gets warm when I do that" (Anna, MA2). High anxiety learners, however, spent a lot of time talking about their own emotions when it comes to 
talking in English. Although emphasizing beliefs about the importance of speaking, they hesitated to do so, using words such as feeling afraid, worried, nervous and embarrassed. This anxiety centered on the risk of making mistakes in front of the others. Consequently, in spite of the unanimously voiced belief that making mistakes is a natural and unavoidable part of language learning, this conviction was overshadowed by the fear of embarrassment for high anxiety learners, as expressed in HA5 (Excerpt 6). Subsequently, the group went on to elaborate on this tension and self-doubt, and the consequences for their behavior in the classroom (Excerpt 7).

\section{Excerpt 6}

I think it's natural to make mistakes, like really natural to say it wrong, because when you're learning English you have to make mistakes . . . but for me, it feels as though the whole class knows English, and, if I speak and say it wrong, then I feel like I am no good at English and that everyone will like laugh, not because they do, but I feel it could happen ... (Sara, HA5)

Excerpt 7

Sara: I don't say anything at circle time, cause I believe I will say the wrong word and like, embarrass myself.

Bea: I usually don't ask anything in the English lessons ... or in circle time, cause it's like ... you get like nervous.

Sara: But ... I don't have like a very good memory when we're sitting in the ring, so I'm not very good at English ...

Bea: No, me neither.

Sara: $\quad$ Cause, I don't remember things very well ... and if I feel that I do remember them ... then I feel like, that maybe it's wrong and then I will make a mistake when I say them. (HA5)

Likewise, interactions in the other high anxiety groups also reflect a conflict between beliefs and emotionally guided behavior and reveal how the TLonly policy plays out in the classroom for the more anxious learners (for example Excerpt 8). The fear of laughter and negative reactions from peers was expressed in strikingly similar ways among the more anxious learners. A few pointed out that, in reality, that does not happen and that they themselves never found it odd or funny when a classmate made a mistake. Yet, the class as a group was perceived as a potential threat, although peers could also offer support when speaking in full class felt intimidating (Excerpt 9).

\section{Excerpt 8}

Kim: And you have to speak English, and then you really try, and then you learn.

Siri: $\quad$ And then you try, but we're a bit cowardly in our class, and we don't talk a lot.

Kim: Yes, we're a bit cowardly. 
Siri: $\quad$ Until she says that we can say things in Swedish, and then everyone raises their hands. (HA6)

Excerpt 9

Emil: $\quad . .$. and when you're standing in the circle, or by the board, sometimes it feels good when a classmate just like whispers a bit, what to say.

Kim: $\quad$ Yes, and helps out.

Emil: $\quad$ When you just like ... lose, what to say.

Kim: $\quad$ Yeah, in the classroom ...

Siri: $\quad$ Lose it, like.

Emil: $\quad$ Like brainfreeze.

Kim: In the classroom I think saying it right is the most important thing, cause I don't dare make mistakes, so I hardly ever say anything. (HA6)

Taken together, the excerpts in this section signal shared beliefs about the importance for the individual learner to engage. However, for the more anxious learners, social considerations appear to govern behavior in contrast to those same beliefs and make them refrain from speaking.

\subsection{Experiences of lesson organization}

Some learners pointed out that working next to someone you can ask, or in pairs, at least with a slightly more proficient partner, felt safer than speaking in full class. Nevertheless, in general, high anxiety learners expressed a preference for full class activities. This way they could benefit from scaffolding offered by the teacher, as she gestured, used the board and pictures, explained, repeated and modeled. They expressed a strong reliance on the teacher. With her instruction and support, learners would understand, learn and remember. Repeating words and phrases after the teacher was much appreciated, also for those with less anxiety. The activity was described in terms of making English "get into your brain" (MA3) and "get stuck to your mouth" (HA6) and helps develop pronunciation. And so, while many high anxiety learners preferred teacher-led activities in full class, they reported feeling inhibited from speaking under those conditions (Excerpt 10). One group in particular went on to discuss their preference for working together in full class (Excerpt 11).

Excerpt 10

Sara: I learn English best, like Bea when we sit in the ring and talk, and, but I don't like speaking a lot.

Erik: $\quad$ Me neither.

Sara: I understand but I don't have a very good memory but like they speak pretty much the same way every time so then I remember better, when you take the words over and over again. (HA5) 
Excerpt 11

Bea: $\quad$ Sometimes it can be a bit difficult ... and stressful when the others are done and we're like last, if you're last ... that can be quite hard . . . when you don't really understand what it says on the worksheet and the teacher can't help you and there are others who don't understand either.

Sara: $\quad$ Yes.

Bea: $\quad$ That can be a bit hard.

Sara: $\quad$ For me, if we get worksheets I like it best when we work together in the whole class.

Bea: $\quad$ Yes, and when she uses the board.

Sara: $\quad$ Yes, when she uses the board, and maybe flashcards and we work together ...I don't like when I'm alone with it, I like it better when it's the group and when we are the whole class, cause when I'm alone it feels a lot harder. $\ldots$

Sara: I'm not very good at English and I feel that I'm going to be last with the worksheets.

Bea: Yes, exactly.

Sara: $\quad$ So I feel stressed ... and a bit difficult. (HA5)

To summarize, the learners expressed similar beliefs reflecting the importance of listening and speaking, and extensive TL input. Perhaps a bit surprisingly, the less anxious learners voiced a more critical attitude towards not understanding everything the teacher said, compared to their peers. Yet, the situation for the more anxious learners in this classroom involved three mismatches, or conflicting ideals, all related to FLA.

\subsection{Mismatches between beliefs and/ or experiences}

The first mismatch revolves around incomprehensible input. All group discussions reflected a positive attitude towards the immersive approach adopted by the teacher, and the high anxiety learners questioned it less than their more confident peers did. Nevertheless, from the observations and the group discussions it was clear that a monolingual approach was a hindrance for these learners. They admitted missing out on instructions and not being able to understand the content of classroom talk, which generated negative emotion and frustration and inhibited their oral participation. These high anxiety learners, however, remained loyal to the teacher and her monolingual approach, and did not blame their unwillingness to communicate on the lack of comprehensible input, but rather on their inadequate proficiency and bad memory.

The second mismatch relates to high anxiety learners' beliefs about their own role and actions. On the one hand, learners expressed a conviction about the importance of speaking and that they must engage and dare communicate. 
On the other hand, many of them admitted that they refrain from interacting due to fear of making oral mistakes and receiving negative reactions from peers. The learners were thus not able to act in accordance with the beliefs that they expressed.

The third mismatch concerns the organization of lessons. High anxiety learners preferred teacher-led activities in full class, where they received multimodal support. Ironically, this was exactly the situation in which they did not feel comfortable enough to ask questions or volunteer to speak. Another benefit of working in full class was that learners did not risk falling behind, a fear anchored in their own experiences from working with individual tasks. There was thus a gap between this preference for input in full-class and the negative feelings associated with interaction in the same setting.

In the simultaneous group discussions, learners in all groups referred to their own experiences as they voiced their opinions and preferences about useful activities and classroom practices. All the three mismatches identified among the high anxiety learners involved negative emotional experiences, related to speaking English in class. Such situations were perceived as vicious cycles where negative emotions themselves had a detrimental effect on their ability to recall vocabulary and avoid mistakes. The high anxiety learners pointed to the importance of peers, teacher and classroom atmosphere, and shared their concerns about comparison to others, false fear of laughter and reluctance to guess, which influenced their behavior and self-concept.

\section{Discussion}

The language learners in this case study shed light on the close interaction between learner beliefs, emotion and behavior, as well as learners' perceptions of situated needs and constraints. The context of the present study is interesting since the English lessons with this teacher constitute the learners' joint history of language instruction and is thus the same for all of the participants. Within this classroom, similar beliefs but quite varying experiences of FLA emerged. In this section, findings are interpreted and discussed in relation to the research questions. Subsequently, implications for language teaching are addressed.

The first research question concerns the expressed beliefs and experiences of the young participants. In general, and regardless of anxiety levels, the YLLS voiced beliefs similar to those of their peers and their teacher. Although many learners found monolingual teaching to be challenging, they expressed support for the approach and stressed the need for extensive TL use. As for their role as learners, they highlighted the importance of daring to speak, guess, and engage.

The current findings offer support for the impact of the teacher on YLL beliefs (Aro, 2009). It is likely that the beliefs articulated in this study were appropriated from 
the teacher, who is perceived as the expert and a much-appreciated adult for these beginner language learners. Their voices may also reflect the beliefs of parents (in turn potentially impacted by the teacher). A further possibility is that learners consciously echo the beliefs of their teacher, believing that they ought to. Regardless, the discussions demonstrate that the beliefs about desired learning behavior have a strong impact on the way learners assess their own performance.

In response to the second research question, while learner beliefs were shared among learners of varying anxiety levels, their expressed experiences of oral classroom interaction differed. Notably, although discussion prompts focused on beliefs about teaching and learning, all groups brought up aspects of emotional experiences. The accounts of the high anxiety learners reveal the profound impact of FLA on their learning experience. Their worries center around speaking in front of peers and are strikingly similar to accounts from adult learners (Gkonou, 2017). The findings thus offer further evidence for the strong affective impact on the learning process of young learners, echoing findings by Kuchah and Pinter (2012).

In response to the third research question, three mismatches related to beliefs and experiences were found among high anxiety learners in the present classroom, all directly or indirectly related to speaking. Firstly, although these learners expressed strong support for extensive TL input, they feared situations in which they were not able to respond or act appropriately, for lack of understanding. Secondly, like their peers, they underscored the importance of daring to speak although they themselves admitted to refraining from interacting, to reduce social exposure and the risk of making mistakes in front of peers. Thirdly, while preferring full class teaching modes, as this means that they can benefit from multimodal scaffolding and keep the pace of the rest of the class, this situation inhibits them from engaging and asking for clarifications. The perspectives of these high anxiety language learners thus illustrate a situation where they feel unable to live up to the shared classroom ideals.

Researchers have encouraged teachers to address and reflect on teaching approaches and beliefs with older students (Aragão, 2011; Brown, 2009; GarcíaPonce et al., 2018; Kalaja et al., 2018) to improve classroom atmosphere and motivation, and mitigate anxiety. In this case, rather than have learners share and reflect on their own beliefs and perceptions, the teacher spoke enthusiastically about the benefits of exclusive TL input in order to convince learners and have them accept not always understanding. Presumably, the intention was to counteract FLA. Indeed, discrepancies between the teacher and learner beliefs are possible sources of FLA (Brown, 2009; García-Ponce et al., 2018; Kalaja \& Barcelos, 2013). In the present context, however, the identified mismatches are not the result of competing beliefs. Rather, the fact that learners share the beliefs of 
the teacher (for whatever reason) creates a cognitive and emotional dissonance for high anxiety learners, while they remain loyal to the approach of the teacher.

In this TL-only context, learners reported that negative emotions guide behavior in stark contrast to their beliefs about the importance of speaking, echoing results from studies with university students (García-Ponce et al., 2018; Yoshida, 2013). With this tension, their perceived ability to act within the classroom, that is, their sense of agency, was restricted. They nevertheless remained loyal to the language learner beliefs shared in the classroom and instead blamed themselves, their lack of proficiency or their personality, which itself has a negative impact on their self-concept and their emotion. Similarly, in a study by Gkonou (2015), anxious adult learners of English concluded that their avoidance behaviors and non-actions increased their FLA further. Arguably, the cognitive and emotional challenge of oral performance for high anxiety learners in this situation is likely to decrease the zone of proximal development, as suggested by M ahn and John-Steiner (2002). As both a sense of agency and the prevention of anxiety have been identified as crucial for early language learning, these findings may be relevant to consider in other instructional contexts as well.

According to Kalaja et al. (2016), agency and beliefs overlap, with emotion serving as background (see Figure 1, Section 2.2.). The present findings stress a strong influence of emotions on agency. In this context, a sense of agency may in fact be conceptualized as the overlap between beliefs and emotion (see Figure 2). In situations where learners feel that their emotions align with their own beliefs and expectations, the overlap is large and learners' perception of their action potential increases. However, beliefs about teaching and learning do not always correspond with the emotional readiness to act in accordance with those beliefs, as is the case with the high anxiety learners in the current classroom. The sense of agency is thus reduced, which in turn has a negative effect on selfconcept. In this situation, learners make sense of the situation by blaming their perceived incompetence and referring to themselves as cowardly or less proficient.

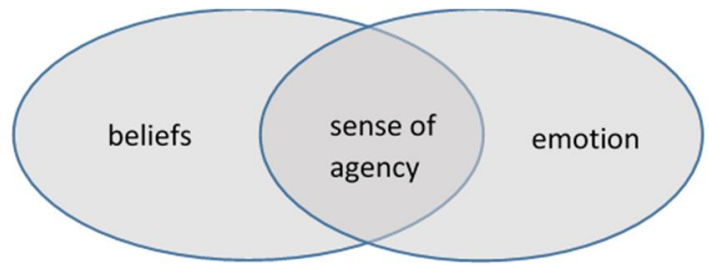

Figure 2 Sense of agency as an overlap between learner beliefs and emotion

The findings have possible implications for teaching practices. The learners in this classroom seemed convinced about the benefits of extensive TL input. 
At the same time, many of them frequently experienced FLA. No conclusion can be drawn about monolingual teaching as the cause of FLA. As in all classrooms, many learner variables come into play, such as personal aptitude and language proficiency of each learner, variables that were not considered in this study. Nevertheless, according to the learners who often experience FLA and are reluctant to participate orally, the TL-only approach presents a major constraint. Their accounts suggest that the monolingual policy decreases engagement and their ability to benefit from instructions and explanations, and respond to prompts. Copland and $\mathrm{Ni}$ (2019) argue that creating a low-anxiety classroom should be a primary concern for teachers of YLLs, which involves flexible language use and sensitivity to learner reactions and responses. A reconsideration of monolingual language teaching for this age group has gained ground among researchers (e.g., Macaro \& Lee, 2013). As a TL-only approach is recommended, or even mandated, in many other educational contexts (Copland \& Ni, 2019), the mismatches found may have bearing in other classrooms with YLLs. Arguably, afforded instructions, modelling and scaffolding must be comprehensible to learners. Allowing for students to draw on their L1 resources may thus be more effective, in order to encourage and empower learners to respond and interact. Other implications point to organizational lesson aspects and the need for non-threatening opportunities to speak and practice in pairs or small groups. Offering YLLs more time to talk and fewer interlocutors may itself reduce the risk of anxiety and give learners the experience of successful communication that is important for their self-concept (Arnold, 2011). If not, learners' cognitive processing may be severely impaired by negative emotions (Arnold, 2011; Mahn \& John-Steiner, 2002). From the perspective of the model above (see Figure 2 ), teachers should thus consider ways of helping learners push the circles closer together.

\section{Conclusion}

The present study investigated the beliefs and experiences of YLLs in a Swedish TL-only English classroom. In this particular case, the collective nature of learner beliefs was evident as learners expressed beliefs similar to those of their peers and also in alignment with the instructional approach of the teacher. This is not very surprising since the learners had had all their foreign language lessons in this classroom with the same teacher. Nevertheless, affective and behavioral responses to instruction varied greatly and according to the high anxiety learners, English education involves contradictory beliefs and behaviors, creating a negative cycle where they conclude their own incompetence. The findings thus illustrate the contextual and interrelated dynamics of language learner beliefs, foreign language anxiety and a sense of agency. Although the perspectives and experiences 
of the YLLs in this classroom are unique, the case study reveals mismatches and challenges that may face learners, and their teachers, in other contexts as well. The findings also suggest that the possible consequences of monolingual foreign language instruction for YLLs should be considered carefully.

Using group discussions to collect data has its limitations. It is possible that peer pressure played a role and led some learners to withhold their actual opinions. For this reason, thorough instructions about the purpose of data collection and stressing that the items discussed did not have a right or wrong answer, were very important. The recordings show how learners co-construct, negotiate and build on each other's ideas in their interactions, without the presence of an adult moderator. It is reasonable to think that interviews conducted with an unfamiliar researcher would have generated less elaborate data. Nevertheless, with the group discussion method opted for in this study, it was not possible to ask for clarifications and further elaborations. Furthermore, there is always a risk of adult researchers misinterpreting what children mean to say (Spyrou, 2011). Involving a second researcher to listen to the recorded discussions and be involved in interpretation and abstraction of categories might therefore have been beneficial.

The project will go on to examine beliefs and experience in seven other classrooms where FLA levels were investigated (Nilsson, 2019). Those classrooms had fewer learners categorized as highly anxious and varying amounts of TL use. Whether similar beliefs and mismatches can be identified there remains to be seen. Further studies are needed on the complex interplay between YLLs' beliefs, emotions and sense of agency, and ways to resolve possible mismatches that learners may experience. The articulate voices and perspectives of these young learners, and their eagerness to participate in the discussions, imply that an important point of departure, for teachers and researchers striving to develop optimal learning conditions for YLLs, is to ask young learners to share their beliefs and experiences. 
References

Aragão, R. (2011). Beliefs and emotions in foreign language learning. System, 39(3), 302-313.

Arnold, J. (2011). Attention to affect in language learning. Anglistik. International Journal of English Studies, 22(1), 11-22.

Aro, M. (2009). Speakers and doers: Polyphony and agency in children's beliefs about language learning (Doctoral dissertation). Jyväskylä: University of Jyväskylä. https://jyx.jyu.fi/bitstream/handle/ 123456789/19882/97895139 35320.pdf

Barcelos, A. M. F., \& Kalaja, P. (2013). Beliefs in second language acquisition: Teacher. In A. C. Chapelle (Ed.), The encyclopedia of applied linguistics. http://doi. org/10.1002/9781405198431.wbeal 10083

Brown, A. V. (2009). Students' and teachers' perceptions of effective foreign language teaching: A comparison of ideals. M odern Language Journal, 93(1), 46-60.

Copland, F., Garton, S., \& Burns, A. (2014). Challenges in teaching English to young learners: Global perspectives and local realities. TESOL Quarterly, 48(4), 738-762.

Copland, F., \& Ni, M. (2019). Languages in the young learner classroom. In S. Garton \& F. Copland (Eds.), The Routledge handbook of teaching English to young learners (pp. 138-153). New York: Routledge.

Csizér, K. \& Kálmán, C. (2019). A study of retrospective and concurrent foreign language learning experiences: A comparative interview study in Hungary. Studies in Second Language Learning and Teaching, 9(1), 225-246.

Dufva, H. (2003). Beliefs in dialogue: A Bakhtinian view. In P. Kalaja \& A. M. F. Barcelos (Eds.), Beliefs about SLA: New research approaches (pp. 131151). New York: Springer.

Dufva, H. (2013). Language learning as dialogue and participation. In E. Christensen, L. Kuure, A. M örch, \& B. Lindström (Eds.), Problem-based learning for the 21st century: New practices and learning environments (pp. 5172). Aalborg: Aalborg University Press.

European Commission. (2012). First European survey on language competences: Final report. https://crell.jrc.ec.europa.eu/sites/default/files/files/eslc/ES LC_Final\%20Report_210612.pdf

García-Pōnce, E. E., Crawford, T., Lengeling, M. M ., \& M ora-Pablo, I. (2018). Complexity and likely influence of teachers' and learners' beliefs about speaking practice: Effects on and implications for communicative approaches. International Journal of Language Studies, 12(1), 125-146. 
Garton, S., \& Copland, F. (2019). Introduction. In S. Garton \& F. Copland (Eds.), The Routledge handbook of teaching English to young learners (pp. 1-10). New York: Routledge.

Gkonou, C. (2015). Agency, anxiety and activity: Understanding the classroom behavior of EFL learners. In P. Deters, X. Gao, E. R. Miller, \& G. Vitonova (Eds.), Theorizing and analyzing agency in second language learning (pp. 195-212). Bristol, UK: Multilingual Matters.

Gkonou, C. (2017). Towards an ecological understanding of language anxiety. In C. Gkonou, M. Daubney, \& J.-M. Dewaele (Eds.), New insights into language anxiety: Theory, research and educational implications (pp. 136-156). Bristol, UK: Multilingual Matters.

Graneheim, U. H., \& Lundman, B. (2004). Qualitative content analysis in nursing research: Concepts, procedures and measures to achieve trustworthiness. Nurse Education Today, 24(2), 105-112.

Horwitz, E. K. (1988). The beliefs about language learning of beginning university foreign language students. M odern Language Journal, 72(3), 283-294.

Horwitz, E. K., Horwitz, M. B., \& Cope, J. (1986). Foreign language classroom anxiety. M odern Language Journal, 70(2), 125-132.

Kalaja, P., \& Barcelos, A. M. F. (2013). Beliefs in second language acquisition: Learner. In A. C. Chapelle (Ed.), The encyclopedia of applied linguistics. http:// doi. org/10.1002/9781405198431.wbeal10083

Kalaja, P., Barcelos, A. M . F., \& Aro, M. (2018). Revisiting research on learner beliefs: Looking back and looking forward. In P. Garrett \& J. M. Cots (Eds.), Routledge handbook of language awareness (pp. 222-237). New York: Routledge.

Kalaja, P., Barcelos, A. M. F., Aro, M ., \& Ruohotie-Lyhty, M. (2016). Beliefs, agency and identity in foreign language learning and teaching. Basingstoke: Palgrave MacMillan.

Kolb, A. (2007). How languages are learnt: Primary children's language learning beliefs. International Journal of Innovation in Language Learning and Teaching, 1(2), 227-241.

Kuchah, K., \& Pinter, A. (2012). "Was this an interview?" Breaking the power barrier in adult-child interviews in an African context. Issues in Educational Research, 22(3), 283-297.

Macaro, E., \& Lee, J. H. (2013). Teacher language background, codeswitching, and English-only instruction: Does age make a difference to learners' attitudes? TESOL Quarterly, 47(4), 717-742.

Mahn, H., \& John-Steiner, V. (2002). The gift of confidence: A Vygotskian view of emotions. In G. Wells \& G. Claxton (Eds.), Learning for life in the 21st century: Sociocultural perspectives on the future of education (pp. 46-58). Cambridge, MA: Blackwell. 
M ercer, S. (2011). Understanding learner agency as a complex dynamic system. System, 39(4), 427-436.

Mihaljević Djigunović, J. (2009). Individual differences in early language programmes. In M. Nikolov (Ed.), The age factor and early language learning (pp. 199-226). Berlin: Mouton de Gruyter.

Mihaljević Djigunović, J. (2012). Attitudes and motivation in early foreign language learning. Ceps Journal, 2(3), 55-74.

M ihaljević Djigunović, J. (2015). Individual differences among young EFL learners: Age- or proficiency-related? A look from the affective learner factors perspective. In J. Mihaljević Djigunović \& M. Medved Krajnović (Eds.), Early learning and teaching of English: New dynamics of primary English (pp. 10-36). Bristol, UK: Multilingual Matters.

Muñoz, C. (2014). Exploring young learners' foreign language learning awareness. Language Awareness, 23(1-2), 24-40.

M uñoz, C. (2017). Tracing trajectories of young learners: Ten years of school English learning. Annual Review of Applied Linguistics, 37, 164-184.

Nilsson, M . (2019). Foreign language anxiety: The case of young learners of English in Swedish primary classrooms. Apples: Journal of Applied Language Studies, 13(2), 1-21.

Ravet, J. (2007). Enabling pupil participation in a study of perceptions of disengagement: Methodological matters. British Journal of Special Education, 34(4), 234-242.

Spyrou, S. (2011). The limits of children's voices: From authenticity to critical, reflexive representation. Childhood, 18(2), 151-165.

Sylvén, L. K. (Ed.). (2019). Investigating content and language integrated learning: Insights from Swedish high schools. Bristol, UK: M ultilingual M atters.

Swedish National Agency for Education. (2011). Syllabi for upper secondary school in English. https:// www.skolverket.se/ download/ 18.4fc05a3f16413 1a74181056/1535372297288/English-swedish-school.pdf

Yim, S. Y., \& Yu, Y. (2011). Validating the English learning anxiety scale for primary school students in Korea. English Teaching, 66(2), 101-121.

Yoshida, R. (2013). Conflict between learners' beliefs and actions: Speaking in the classroom. Language Awareness, 22(4), 371-388. 


\section{APPENDIX}

\section{Questions used in the independent group discussions}

- Do you think it's good or bad that the teacher speaks a lot of English even though the students may not understand everything? Explain what you think.

- Do you think different people learn English in different ways? Tell me.

- What do you think is most important when you speak English - that what you say is correct or that others understand what you mean, although you may say things a bit incorrectly?

- Do you think it's smart to guess when there is a word you don't know in English?

- In your experience, do you learn a lot by practicing and repeating and doing things several times?

- What do you think is the best way to learn how to speak English? Explain what you think.

- In your opinion, what are the most important things to learn in English? Why?

- What is the best way for you to learn English? Tell me.

- Do you think you will be quite good at English once you get older?

- Do you learn best when you listen or when you speak? Explain what you think.

- How do you feel when you are working with something that is new or a bit difficult? Tell me.

- Do you think you learn a lot by imitating and repeating after others? Explain what you think.

- Do you believe it's natural to make mistakes when you learn English? Tell me. 